\title{
Multi-dimensional Understanding of the "Product" in the Marketing Decision Process
}

\author{
Rodica Boier, Ph.D, "Gh. Asachi" Iași Technical University, Romania
}

\begin{abstract}
The paper starts from the observation that students often experience difficulties in identifying the complete set of aspects involved in making product decisions, but also in understanding the correlations established between these elements. The review of the information required by product management reveals a set of interrelated aspects among which the most important refer to: product category; the needs that the product addresses; usage situations and fields; the product life cycle; seasonality of manufacturing/purchasing/usage; the path from technical features, such as attributes and functions, to the benefits (advantages) for the client; "total product"; the set of related products; the tangible/intangible relationship a.s.o. The paper may be used as a checklist to identify the requisite steps in the multidimensional research, which precedes the decision process of the product marketing.
\end{abstract}

\section{Keywords}

Product; marketing; need; product life cycle, total product; service; associated (complementary) product

\section{Introduction}

As verified by practice, the marketing decision may experience failure both in the design and the implementation phase, when a certain aspect of the offering is overlooked, be it an unimportant detail. From this perspective, one must note that the teaching process of shaping the students' marketing skills is frequently deficient due to a sequential approach, lacking the holistic vision, where all parts are interconnected. Moreover, beyond the coherent and integrating approach, what is required is a synergetic approach, aimed at ensuring that all parts work together and complete one other. The various marketing subjects convey information, structure knowledge, train abilities, build abilities and in particular attitudes. All of these however are sometimes confined to the subject's limited, relatively reductionist scope, thus eluding an integrating vision, which would allow the student to make connections and to understand interdependencies and the concrete manner of undergoing the logical and chronological path of the complex, difficult, risky and also challenging process of the marketing decision.

The idea for this paper was suggested by the observation that students often experience difficulties in identifying the complete set of aspects involved in making product decisions, but also in understanding the correlations established between these elements. The choice of this particular theme for the article was further motivated by Yadav's recent paper ${ }^{1}$, which draws attention to the quasi-abandonment of conceptual approaches in research, which now tends to focus exclusively on empirical developments. In terms of its content, the paper will therefore constitute a conceptual approach, intended to fill a void, not so much related to concepts themselves but to the connections among them. Moreover, the paper may be used

1 Yadav, M.S. (2010), „The Decline of Conceptual Articles and Implications for Knowledge Development", Journal of Marketing, 74 (1), p. 1-19. 
as a checklist to identify the requisite steps in the multidimensional research which precedes the decision process of the product marketing.

\begin{tabular}{|c|c|c|c|}
\hline Product category & Set of needs & $\begin{array}{c}\text { Usage situations and } \\
\text { domains }\end{array}$ & Tangible / intangible \\
\hline Product Life Cycle & Seasonality & Associated products & Consumer involvement \\
\hline $\begin{array}{l}\text { Technical features } \rightarrow \\
\text { benefits (advantajes) }\end{array}$ & "Total product" & Rational / emotional & Customer loyalty \\
\hline Consumption visibility & $\begin{array}{lll}\mathbf{P} & \mathbf{R} & \mathbf{O}\end{array}$ & $\begin{array}{lll}\mathbf{U} & \mathbf{C} & \mathbf{T}\end{array}$ & Perceived risk \\
\hline Direct competition & Indirect competition & Product market structure & $\begin{array}{c}\text { Product segmentation } \leftrightarrow \\
\text { market segmentation }\end{array}$ \\
\hline \multicolumn{4}{|c|}{ Buying and consumption/usage behavior } \\
\hline & Customer value & Strategic positioning & \\
\hline
\end{tabular}

Figure 1. Dimensions of the „product” concept in the marketing decision process

The organizations high-performance product marketing are able to leverage with great expertise and talent all the information related to the offering ,at three levels ${ }^{2}$ : (1) the product manager as an individual; (2) the marketing processes related to product management; and (3) the organization structure and role definition.” The review of the information required by product management ${ }^{3}$ reveals a set of interrelated aspects among which the most important refer to: product category; the needs that the product addresses; usage situations and fields; the product life cycle; seasonality of manufacturing/purchasing/usage; the path from technical features, such as attributes and functions, to the benefits (advantages) for the client; "total product"; the set of associated (complementary) products; the tangible/intangible relationship; consumption visibility and/or, as the case may be, the visibility of the consequences of using the product; the relationship reason/emotion in the purchase decision process; customer loyalty; perceived purchase risk; consumer involvement; direct competition; indirect competition by substitutes; product segmentation in agreement with market segmentation; product structure market; the product's typical buying and consumption behaviors; market gaps and product value for the consumer; strategic positioning (Figure 1).

It is worth noting that in this complex context, "customer value" and "strategic positioning" are the broadest, all-encompassing concepts, which derive from the previous above.

Below, we will dwell on the elements which provide a preliminary product description, while those components with a more marked strategic focus will be dealt with in a future article.

${ }^{2}$ Tyagi, R.K., M.S. Sawhney (2010), „High-Performance Product Management: The Impact of Structure, Process, Competencies, and Role Definition", The Journal of Product Innovation Management, 27 (1), p. 83.

${ }^{3}$ Boier, R., L. Țimiraș (2006), Cercetarea de marketing, Editura Performantica, Iasi, p. 52. 


\section{Dimensions of the „product” concept in the marketing decision process}

Product category. Marketing's perspective of the concept of "product" is as broad as possible, as it practically encompasses everything that may be offered in order to meet a particular need. The needs and wants of individuals are satisfied through the consumption of goods. The particular need may be a present need, that the consumer recognizes, or a latent one, which the provider must discover, describe, design an adequate product for and subsequently make it known, by explaining it, to the potential consumer.

Whereas, in marketing's classical understanding, the "product" offered meant only a tangible good or a service, contemporary developments have required a broadening of the potential materialization of the product in unconventional areas, the product being simultaneously a combination of the most different and subtle tangible and intangible goods, information and software, ideas, attitudes or behaviors, people and places, etc. Below, we will use the generic term "product" to designate everything that is offered to one's attention, analysis and purchase, regardless of the actual form it may take, according to the complex marketing perspective.

Before focusing on his own offering, the marketer must not overlook the product category it belongs to, simply because, before buying a particular brand, the consumer considers the category it belongs to. As verified in practice, there are situations when the consumer barely accepts an offering, or even rejects it, basically because it stands for a product category of which he has a negative view. Conversely, on other occasions, the consumer easily accepts an offering, simply because it is proposed on the marketplace within a product category with a strong positive image.

The set of needs the product addresses. Behind the decision to buy a product there is always a reason or a combination of reasons. Behind the rejection of a product there is every time a reason or combination of various reasons - the consumer's conclusion that the product, based on its features, will not meet the specific need to the required extent. The process of designing an effective strategy confronts marketers with a long series of decisive questions for the understanding of consumers: the complexity of the need and the set of needs that the consumers attempt to address, the degree of intensity of the needs, the purposes that the consumer seeks to achieve in the process and the associated motivations, the set of actual products and/or services that the consumer wants to buy in order to meet those needs, etc.

\begin{tabular}{|l|l|l|l|l|l|l|}
\hline Products & 1 & 2 & 3 & 4 & $\ldots$ & $\mathrm{n}$ \\
\hline Product A & & $\sqrt{ }$ & $\sqrt{ }$ & & $\ldots$. & \\
\hline Product B & $\sqrt{ }$ & & & $\sqrt{ }$ & $\ldots$. & \\
\hline Product C & & $\sqrt{ }$ & & $\sqrt{ }$ & $\ldots$. & $\sqrt{ }$ \\
\hline Product ... & & & & & $\ldots$. & $\ldots$ \\
\hline$\ldots \ldots \ldots \ldots$ & $\ldots$. & $\ldots$ & $\ldots$ & $\ldots$. & $\ldots$. & $\ldots$ \\
\hline
\end{tabular}

Figure 2. The products-motives relationship

Source: Rodica Boier (2001), Comportamentul consumatorului, Editura "Gh. Zane" Iași, p. 68

A reaction to complex changes, both those that affect the self and those related to the influences exerted from outside, the consumer's motives must be understood through the prism of their considerable dynamics. There are at least three generating causes of the dynamics of motives. Firstly, one must recognize that human needs are never completely satisfied; consequently, the gap between the desired state and the actual state in terms of meeting the needs constantly generates motives. Secondly, the hierarchy of needs ensures 
that a need once met will motivate the consumer to seek to satisfy a higher need. Finally, once the individual has achieved a particular aspiration level, he will be motivated to aim for a higher level; conversely, the impossibility to achieve a particular aspiration level will determine the individual to scale it back.

The relationship between motives and products can be reflected using a matrix, as shown in figure 2. The motives-products correlation matrix differs from a consumer segment to the other depending on their specific combination of features. Ensuring the agreement between the needs and motives of a consumer, on the one hand, and the set of products that can satisfy him, on the other, can be a challenging endeavor. This constitutes in fact the core of the marketing effort of companies.

Product usage situations and domains. The field of use sometimes decisively influences the product configuration, its associated services, its seasonality, etc. It is to be expected that the same product, designed for different fields, will have features customized for the requirements of each particular field. The more the product is customized for the specific field of use, the greater the chances that it will generate consumer satisfaction.

Usage, on the other hand, refers to the different contexts in which the same product may be used. In the Ansoff matrix, the sales growth strategy for an existing product on an existing market is based, among other things, on this solution, i.e. finding alternative uses of the product. Most often, they are discovered by "innovative" consumers, who find ways to use the same products for different applications or fields.

Last, but not last, important among the product usage is the product's capacity to act as a gift, on specific occasions. Generally, the information on this potential product type is obtained through marketing research. If the marketer identifies such a favorable situation, he must subsequently find a solution to suggest to the consumer to buy the product for this specific purpose.

Product life cycle. The stages that the product goes through from introduction up to the withdrawal from the market, and the varying strategic objectives, sales and profits, consumers, competition and marketing efforts involved, represents a major dimension of the decision process. As part of an effective management of the product range, the organization seeks to maintain an internal balance, with products at different in different life-cycle phases, in order to eliminate the disadvantages of each stage and to compensate potential losses on some products with profits on other products.

Essentially related to the product's first life-cycle phase, the new product diffusion process involves the classification chart, which focuses on the relative time required for customers to adopt a new product and on how they use available information sources in the purchasing process. The purchasing moment is measured based on the time between the moment when the consumer becomes aware of the product and the instant when he decides to buy it. The marketer will therefore wish to know the size and characteristics of the various adopter categories, defined in terms of how innovation diffuses in the community as a whole. Between absolute openness, on the one hand, and the absolute resistance to innovation, on the other, there is a range of several intermediate attitudes: innovators, early adopters, early majority, late majority and laggards, each with their own profile and consequences. ${ }^{4}$

Over the product life cycle, one can control the extent to which the product delivers satisfaction to consumers. To observe how this objective can achieved, it can be useful to represent the product using levels which reflect the consumer's different expections: generic product, which simply represents the "good", with the basic name of the product class, without which the product cannot penetrate the market; expected product, the sum of the customers' minimum hopes for the product, resulting from experience in consumption; developed product, which exceeds the consumer's expectations; potential product, which

\footnotetext{
${ }^{4}$ Wejnert, B. (2002), "Integrating Models of Diffusion of Innovations: A Conceptual Framework", Review of Sociology, 28, p. 297-306.
} 
includes any virtual element of a future configuration, designed to attract and retain customers.

Several considerations are of practical relevance for the marketing decision ${ }^{5}$. Firstly, the criterion used for this classification is the product's degree of specialization, in relationship to consumers' expectations. Secondly, the developed product represents, through its components, more than the customer states as a need/want at a given moment, beyond what he expects or used to expect. As a result of the regular release of upgrades and of the mechanism of experience effect, the consumer learns to hope for reasonable product improvements. Customer expectations interact with the manufacturer's product upgrades, meaning that the product evolves throughout its life cycle. As a matter of fact, the developed product is typical of mature markets, featuring experienced, or even sophisticated customers. Thirdly, the potential product reflects the maximum improvements it can receive. The difference between the potential product and the developed product anticipates, at any given moment, what is still possible and simultaneously what remains to be done. However, the border of the potential product is fluid and cannot be accurately traced in advance. Finally, the path of an upgrade feature goes in the opposite direction of consumers' expectations: as a possible upgrade feature becomes a differentiated product, it will end up, sequentially, as a component of the developed product. Eventually, customers become accustomed to the feature, which turns into a minimal expectation, incorporated in the expected product field.

Seasonality in manufacturing/purchasing/usage. Product strategy decisions are largely influenced by its potential seasonality. Seasonality derives essentially from consumption patterns, yet there are situations where certain aspects of manufacturing or even distribution may cause seasonality ${ }^{6}$ (for example, the availability of raw materials). Generally, the seasonality of consumption, if it exists, will impose specific demands on distribution and thereby on manufacturing. Therefore, the typical consumption patterns and, accordingly, the distribution and even manufacturing patterns must be known and understood properly, prior to making any marketing decisions. At the same time, the factors that cause seasonality, no matter its type, are thoroughly examined, in order to identify potential solutions that will lead to its reduction.

Technical features, functions, features and benefits (advantages) for the customer. Marketing theory has provided one further answer to the research undertakings relevant for this article: it is not the article in itself that generates satisfaction, but rather the features (benefits) it consists of or, more precisely, the advantages it brings to the customer. The individual does not research the market to purchase products as mere things, but as combinations of benefits that they provide; he will not buy the product only to possess it, but for the utility it offers in consumption; in other words, consumers will look not for products, but rather for solutions to their problems. "Many sellers make the mistake of paying more attention to the specific products they offer than to the benefits and experiences produced by these products."

The "total product". The product can be represented tridimensionally as follows ${ }^{8}$ : core customer value, the essential level, which reveals, beyond any specific features, the benefits that the customers actually seek; actual product, a particular materialization of the core product, most often under a different name, and features, styling, brand name, packaging and

${ }^{5}$ Boier, R. (1997), Inovare şi succes. Strategii de marketing pentru produse noi, Editura Sedcom Libris, Iaşi, p. 31-32.

${ }^{6}$ Favaretto, D., Bruno Viscolani (2004), “A General Model for the Marketing of Seasonal Products”, Journal of Interdisciplinary Mathematics, 7, p. 349-366.

${ }^{7}$ Kotler, P., G. Armstrong (2010), Principles of Marketing, 13th Edition, Pearson Education, Upper Saddle River, NJ, p. 30.

${ }^{8}$ Kotler, Armstrong (2010), p. 249. 
quality level; augmented product, incorporating the additional consumer services which complement the actual, tangible product. According to this view, the last two levels of a product include its tangible and intangible basis, which delivers the benefits that the customer expects. The components that shape the levels two and three may also be evaluated in terms of their structural features (physical characteristics), functional features (performance) and aesthetics (style, color).

By adopting this structure, the product manager is expected to undertake the following actions in succession: identifying the basic needs that the product will meet; designing of the actual tangible product and its components; devising the set of benefits that will complete the product and enable it to meet customer expectations to the highest degree.

Associated (complementary) products. There are relatively few situations when a certain need is met through the consumption of a single product. In most cases, ensuring the consumer's complete satisfaction hinges on the combined consumption of several products, which thereby associate with one another and combine into what marketing designates as set of associated products. The more complex the need, the more likely it is that the set of associated products will be particularly complex in terms of content.

In estimating the product value, the consumer seeks to anticipate, in addition to the delivered utility, the costs entailed by the acquisition, ownership, consumption/usage of the product and, where applicable, the disposal costs. All the listed situations involve products and services associated with the actual product. Sometimes, there are cases when a consumer's financial burden, resulting from the associated products (transport, installation and start-up costs, consumables, energy and fuel, repairs, spare parts, etc) exceeds the purchasing cost of the actual product.

Tangible/intangible relationship. One of the most conspicuous developments in recent years has been the marked growth of the service sector. A service is, in essence, a particular form that the offered product may take. Practically, any product nowadays incorporates services. Similarly, there are few cases when a service does not include a more or less broad range of several tangible products. One may therefore speak of a product-service continuum $^{9}$, as a structure where the tangible and intangible mix varies depending on the features of the offering and the profile of the customer segment. Within this combination, services add value to the product and similarly support products add value to the provided service. Consequently, product marketing will consider these facts and will focus on solutions to enhance the value delivered to the customer, from the earliest product configuration phase, but equally in the subsequent stages, of manufacturing, distribution, communication and after-sale support. Furthermore, the marketer's task will be to find the optimal solutions for managing service-related issues - intangibility, inseparability, variability and perishability - by means both of internal marketing and of external and interactive marketing efforts ${ }^{10}$.

\footnotetext{
${ }^{9}$ Curtis Tony (2008), Marketing for Engineers, Scientists and Technologists, John Wiley \& Sons, Ltd, Chichester, p. 85.

${ }^{10}$ Gary Armstrong, Philip Kotler (2009), Marketing. An Introduction, 9th Edition, Pearson Education International, Inc., Upper Saddle River, NJ, p. 254.
} 


\section{References}

1. Armstrong, Gary, Philip Kotler (2009), Marketing. An Introduction, 9th Edition, Pearson Education International, Inc., Upper Saddle River, NJ.

2. Boier, R., Laura Ţimiraş (2006), Cercetarea de marketing, Editura Performantica, Iaşi.

3. Boier, R. (2001), Comportamentul consumatorului, Editura "Gh. Zane" Iași.

4. Boier, R. (1997), Inovare şi succes. Strategii de marketing pentru produse noi, Editura Sedcom Libris, Iaşi.

5. Curtis, Tony (2008), Marketing for Engineers, Scientists and Technologists, John Wiley \& Sons, Ltd, Chichester.

6. Favaretto, D., Bruno Viscolani (2004), "A General Model for the Marketing of Seasonal Products", Journal of Interdisciplinary Mathematics, 7, p. 349-366.

7. Kotler, P., G. Armstrong (2010), Principles of Marketing, 13th Edition, Pearson Education, Upper Saddle River, NJ.

8. Tyagi, R.K., M.S. Sawhney (2010), „High-Performance Product Management: The Impact of Structure, Process, Competencies, and Role Definition”, The Journal of Product Innovation Management, 27 (1), p. 83-96.â

9. Wejnert, B. (2002), "Integrating Models of Diffusion of Innovations: A Conceptual Framework", Annual Review of Sociology, 28, p. 297-306.

10. Yadav, Manjit S. (2010), „The Decline of Conceptual Articles and Implications for Knowdlege Development" Journal of Marketing, 74 (1), p. 1-19. 